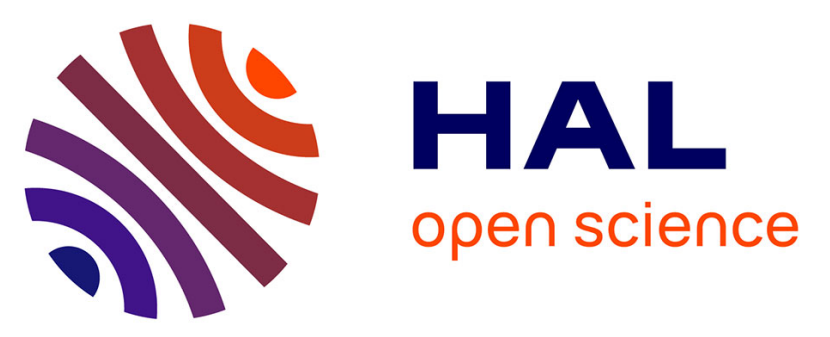

\title{
From Electronic Waste to Suzuki-Miyaura Cross-Coupling Reaction in Water: Direct Valuation of Recycled Palladium in Catalysis
}

Valentin Lacanau, Françoise Bonnete, Patrick Wagner, Christiane Contino-pépin, Martine Schmitt, Daniel Meyer, Frédéric Bihel, Christiane Contino-Pépin, Damien Bourgeois

\section{To cite this version:}

Valentin Lacanau, Françoise Bonnete, Patrick Wagner, Christiane Contino-pépin, Martine Schmitt, et al.. From Electronic Waste to Suzuki-Miyaura Cross-Coupling Reaction in Water: Direct Valuation of Recycled Palladium in Catalysis. ChemSusChem, 2020, 13 (19), pp.5224-5230. 10.1002/cssc.202001155 . hal-02999762

\section{HAL Id: hal-02999762 \\ https://hal.umontpellier.fr/hal-02999762}

Submitted on 20 Nov 2020

HAL is a multi-disciplinary open access archive for the deposit and dissemination of scientific research documents, whether they are published or not. The documents may come from teaching and research institutions in France or abroad, or from public or private research centers.
L'archive ouverte pluridisciplinaire HAL, est destinée au dépôt et à la diffusion de documents scientifiques de niveau recherche, publiés ou non, émanant des établissements d'enseignement et de recherche français ou étrangers, des laboratoires publics ou privés. 


\section{From electronic waste to Suzuki-Miyaura reaction in}

\section{water: direct valuation of recycled palladium in}

\section{catalysis}

Valentin Lacanau, ${ }^{[\mathrm{a}, \mathrm{b}]}$ Françoise Bonneté, ${ }^{[\mathrm{b}, \mathrm{c}, \mathrm{d}]}$ Patrick Wagner, ${ }^{[\mathrm{e}]}$ Martine

Schmitt, ${ }^{[\mathrm{e}]}$ Daniel Meyer, ${ }^{[\mathrm{a}]}$ Frédéric Bihel, ${ }^{[\mathrm{e}]}$ Christiane Contino-Pépin, ${ }^{[\mathrm{b}]}$ and Damien Bourgeois* ${ }^{[\mathrm{a}]}$

[a] Dr. V. Lacanau, Dr. D. Meyer, Dr. D. Bourgeois

Institut de Chimie Séparative de Marcoule,

ICSM, CEA, CNRS, ENSCM, Université de Montpellier

BP 17171, Marcoule, 30207 Bagnols-sur-Cèze, France.

E-mail: damien.bourgeois@umontpellier.fr

[b] Dr. V. Lacanau, Dr. F. Bonneté, Dr. C. Contino-Pépin

Equipe Chimie Bioorganique et Systèmes Amphiphiles

Institut des Biomolécules Max Mousseron, UMR 5247

Avignon Université, 84911 Avignon, France.

[c] Dr. F. Bonneté

Université de Paris

LBPC-PM, CNRS, F-75005 Paris, France.

[d] Dr. F. Bonneté

Institut de Biologie Physico-Chimique

F-75005 Paris, France.

[e] P. Wagner, Dr. M. Schmitt, Dr. F. Bihel

Laboratoire d'Innovation thérapeutique, UMR 7200

Labex Medalis, CNRS, Université de Strasbourg, Faculté de Pharmacie

74 route du Rhin, BP 60024, 67401 Illkirch, France

Supporting information for this article is given via a link at the end of the document. 
Abstract: From electronic waste to catalysis! The straightforward valuation of palladium recovered from electronic waste is reported here. Following a classical leaching stage, palladium is selectively extracted from a complex aqueous mixture of metallic cations into an organic phase. Afterwards, the judicious choice of a surfactant enables stabilization of palladium during back-extraction cycles, and the direct preparation of an aqueous micellar solution, which can be employed in a model Suzuki-Miyaura cross-coupling reaction. Clean phase separation is observed, and distribution of all components between organic and aqueous phases is mastered. The proposed process avoids tedious waste generating steps, dedicated to palladium isolation and to the preparation of palladium pre-catalyst. This novel approach enables a better use of our natural resources, through new cycles in circular economy.

\section{Introduction}

Palladium is a rare precious metal, well known for its numerous applications in catalysis. ${ }^{[1]}$ However, further development of Pd-catalyzed reactions at industrial scale suffers from the high cost of this metal, which now regularly exceeds that of gold. Although numerous efficient atom-economical reactions are available using homogeneous Pd catalysis, their cost is not competitive with classical synthesis, which often requires more steps and generates more effluents. ${ }^{[2]}$ Recently, the boom in Pd-catalyzed reactions in water, thanks to micellar catalysis, ${ }^{[3-5]}$ opens a new chapter in the field of user-friendly chemistry, and the reduction of the Pd cost would definitely enable wider use of such reactions. The cost of Pd is mainly due to its rare occurrence in the earth's crust (ca. $15 \mu \mathrm{g} / \mathrm{kg}$ ), accompanied by a narrow distribution of deposits: today more than $80 \% \mathrm{Pd}$ is mined in South Africa (SA) and Russia, with most of the reserves located in SA. ${ }^{[6,7]}$ Whatever the ore treated, Pd is obtained after thorough purification, as a by-product of nickel (Russia) or platinum (SA). Economical and geopolitical analyses of natural resources have led to the inclusion of platinum group metals (PGM, which include Pd) in lists of critical raw materials by the European Union (EU) and the United States Geological Survey (USGS). ${ }^{[\mathbf{8 , 9}]}$ As a consequence, especially for Western and Asian countries (Europe, United States, China, Japan...), Pd mining from the so-called 'urban mine' is nowadays more and more considered. ${ }^{[10,11]}$ Already, Pd contained in automotive catalytic converters is widely recycled, along with $\mathrm{Pt}$ and $\mathrm{Rh}^{[12]}$ And although gold and copper remain the 
principal targets of studies related to valuable metal production from metallic waste, several solutions regarding Pd recovery from electronic waste have been proposed. ${ }^{[12-15]}$

Whatever its source, natural ore or waste, Pd is separated from other metals and isolated via hydrometallurgy, combining selective precipitation and liquid-liquid (L/L) extraction steps. Liquid-liquid extraction (or solvent extraction) is an efficient technique which is widely employed at industrial scale for the refinement of metals obtained from natural ores, such as copper, nickel and PGM. ${ }^{[16-18]}$ It enables metal separation and isolation through its selective extraction from an aqueous phase into an organic phase, based on specific complexing agents (extractants). Possible impurities contained in the organic phase are then removed by washing with water or dilute acid aqueous solution (scrubbing stage). The target metal remaining in the organic phase is afterwards back-extracted into a specific aqueous layer, and the organic phase is re-employed in a new extraction cycle. In the specific case of palladium, the metallic cation is back-extracted from the organic phase into a chloride aqueous phase, and usually precipitated as a $\mathrm{Pd}(\mathrm{II})$ salt $\left(\left[\mathrm{Pd}\left(\mathrm{NH}_{3}\right)_{4}\right] \mathrm{Cl}_{2}\right)$ with ammonia and hydrochloric acid, filtered and dried. ${ }^{[19]}$ Pd sponge is eventually obtained after burning $\left[\mathrm{Pd}\left(\mathrm{NH}_{3}\right)_{4}\right] \mathrm{Cl}_{2}$, and metallic $\mathrm{Pd}$ can be further refined using electrowinning. ${ }^{[20]}$ Recycled Pd and natural Pd both join the same industrial applications routes only after these extra steps.

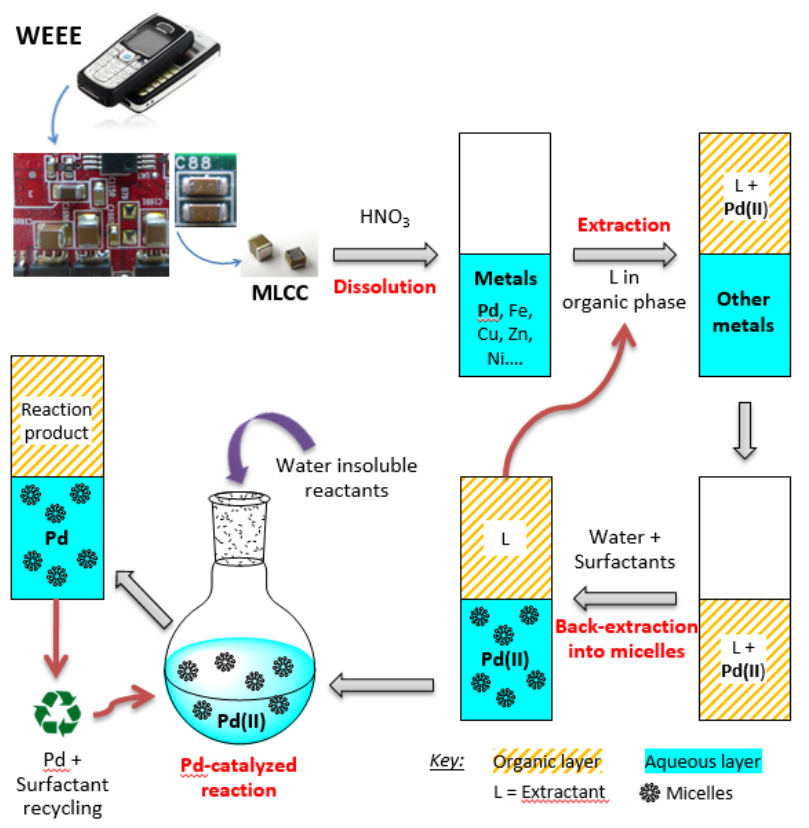


Figure 1. Principle for the direct use in micellar catalysis of Pd recovered from waste of electrical and electronic equipment (WEEE). L = bis(2-ethylhexyl)sulfoxide $(\mathrm{BESO})$, or $N, N^{\prime}$-dimethyl, $N, N^{\prime}$-dibutyltetradecylmalonamide $(\mathrm{MA})$. MLCC = multi-layer ceramic capacitors.

In order to avoid the tedious and effluent generating steps dedicated to $\mathrm{Pd}$ isolation and ultimate purification, we propose in the present work a simple process dedicated to the direct use of Pd contained in organic extraction phases into micellar catalysed reactions in water. This process is especially interesting as it enables the straightforward valuation of $\mathrm{Pd}$ recovered from waste, after its separation from other metals with L/L extraction. The key step in the process lies in the direct back-extraction of Pd from the organic phase into an aqueous micellar phase (Figure 1). We studied the resulting micellar phase, and demonstrated that it shows similar catalytic activity as conventional micellar media prepared from commercial $\mathrm{Pd}(\mathrm{II})$ salt $\left(\mathrm{Pd}(\mathrm{OAc})_{2}\right)$. Such a process skips steps required for Pd isolation, as well as inherent reduction-oxidation steps, and subsequent preparation of a well-defined Pd(II) intermediate.

Various sustainable approaches to catalysts have been proposed to overcome the limitations of the global supplies of precious metals. ${ }^{[21]}$ The trash-to-resource approach has been proposed on model three-way catalysts prepared at the laboratory using $\mathrm{Pd}$ only: ${ }^{[22]}$ Leaching of metallic $\mathrm{Pd}$ using organic reagents enables the formation of a Pd(II) complex, ${ }^{[22]}$ which can be either decomposed into nanoparticles to obtain a heterogeneous catalyst, ${ }^{[23]}$ or subject of ligand exchange to obtain molecular catalysts. ${ }^{[24,25]}$ Harvesting $\mathrm{Pd}$ dispersed in the environment appears as an appealing complementary solution, thanks to phytoextraction, ${ }^{[26]}$ considering the possible use of 'green' $\mathrm{Pd}$ recovered from plants directly into catalysed reactions. ${ }^{[27,28]}$ But latter proof of concept was based on rhizofiltration of a synthetic solution containing solely $\mathrm{Pd},{ }^{[27]}$ and levels of $\mathrm{Pd}$ accumulation in plants after phytoextraction from soil are below that required for active Pd-catalysts. ${ }^{[26]}$ Thus, to our knowledge, the direct use of Pd recovered from a complex mixture of metals such as those found in wastes has never been evidenced so far.

The reprocessing of electronic waste is a very complex procedure, based on physical and chemical operations. ${ }^{[15,29]}$ Detailed analysis of available literature reveals that no satisfactory Pd isolation has ever been reported using processes based on waste grinding followed by complete digestion with aqua Regia $\left(\mathrm{HCl} / \mathrm{HNO}_{3}\right.$ mixture $){ }^{[19]} \mathrm{Pd}$ is mainly found in waste of electrical and electronic equipment (WEEE) as 
Ag/Pd alloy in multi-layer ceramic capacitors (MLCC). ${ }^{[30]}$ Separation of components, including MLCC, from printed-circuit boards can be easily performed after dissolution of $\mathrm{Sn} / \mathrm{Pb}$ solders. ${ }^{[31,32]} \mathrm{We}$ recently demonstrated that the Pd-based alloy found in so recovered MLCC is readily dissolved into $3 \mathrm{M}$ aqueous nitric acid, without generation of $\mathrm{NO}_{\mathrm{x}}$ gases. ${ }^{[19]}$ Thus, Pd present in WEEE can be available as Pd(II) in a relatively simple aqueous nitrate solution, which contains base metals such as $\mathrm{Cu}, \mathrm{Ni}, \mathrm{Co}, \mathrm{Zn}, \mathrm{La}, \mathrm{Fe}$ or $\mathrm{Al}$ (Figure 1), and leaving most $\mathrm{Au}$ and $\mathrm{Cu}$ on the naked board ${ }^{[19]} \mathrm{We}$ previously reported the selective extraction of Pd from this mixture, using either a sulfoxide (bis(2-ethylhexyl)sulfoxide, BESO) or a diamide ( $N, N^{\prime}$-dimethyl, $N, N^{\prime}$-dibutyltetradecylmalonamide, $\left.\mathrm{MA}\right)$ extractant $\quad($ see $\quad$ Figure $\mathrm{S} 1$ in supplementary information for chemical structures). ${ }^{[13,19]}$ Both molecules are available, stable, have extremely low water solubility, and have been employed in continuous pre-industrial extraction processes. The purpose of the present work is to evaluate the feasibility of the valuation of the organic phases obtained after Pd extraction.

\section{Results and Discussion}

The dissolution of Pd contained in MLCC isolated from boards recovered from various end of use electronic apparatus (see Figure S2 in supplementary information) was performed using $3 \mathrm{M}$ aqueous nitric acid according to the process we developed recently. ${ }^{[19]}$ A solution containing Pd along with $\mathrm{Cu}, \mathrm{Fe}$ and $\mathrm{Ni}$ as major impurities was obtained (Table 1, see Table S1 in supplementary information for complete data). Pd extraction was studied in detail using two organic phases: a 0,5 M MA solution in toluene, and a 0,2 M BESO solution in $n$-heptane. The Pd distribution coefficient is higher than 50 with BESO, so that quantitative $\mathrm{Pd}$ extraction is obtained, even with a phase volume ratio of $3 / 1$ (aqueous/organic), which enables Pd concentration in the organic phase (Table 1). With MA, the lower distribution ratio $(\mathrm{D}=16)$ enables almost complete Pd extraction (99\% yield) after a two-stage crosscurrent extraction step (Table 1). Little $\mathrm{Cu}$ is extracted with both systems, and relatively important $\mathrm{Fe}$ amount is co-extracted with MA (Table 1). Ni could not be detected in the organic phase; other metals also present in the leachate in lower amount $(\mathrm{Ag}, \mathrm{Pb}, \mathrm{Sn}, \mathrm{Zn}$, see Table $\mathrm{S} 1$ in supplementary information), have distribution coefficients much lower than that of $\mathrm{Fe},{ }^{[19]}$ and could not be detected in 
the final organic phases. These results are in full agreement with previous results from our laboratory regarding $\mathrm{BESO}^{[13]}$ and $\mathrm{MA},{ }^{[19]}$ and prove the robustness of these extracting systems according to the variations of the composition of the initial leachate. Washing of the organic phase with a small amount of water (volume phase ratio organic/aqueous of 10) is possible without measurable loss of $\mathrm{Pd}$ from the organic layer (less than $1 \%$ ), and enables to bring concentrations of unwanted metals below limit of detection (LoD) in the case of BESO (Table 1). In the case of MA, there is still a small amount of Fe and $\mathrm{Cu}$ (Table 1), which removal could be envisioned using a second washing with dilute nitric acid, albeit with $4 \%$ Pd loss, as observed during our previous studies, and which was not attempted here. ${ }^{[19]}$

According to the extractant chosen, $\mathrm{Pd}(\mathrm{II})$ is stabilized in the organic phase mostly through coordination in the first sphere of the metallic cation, by the extractant and two nitrate anions, to ensure electro neutrality of the supramolecular species. ${ }^{[18,33]}$ Our experimental results are in full agreement with previous data which suggest a higher stability of the Pd-sulfoxide complex in comparison with the Pdmalonamide complex, which (relative) stability was quite suprising. ${ }^{[17,18]}$ Back-extraction into the aqueous layer relies either on poor stability of former coordination complex, or on formation of a more stable complex in the aqueous layer. BESO is more efficient than MA for extraction stage, but quantitative Pd back-extraction into aqueous phase requires aqueous Pd-stabilizing agents (ammonia, thiourea...). With MA, we previously proved that back-extraction can be almost quantitative without any added reagent, as long as the aqueous nitrate concentration is low. ${ }^{[13]}$ Both organic phases containing Pd arising from WEEE processing are thus available, and were examined in the following Pd backextraction studies.

Table 1. Preparation of organic phases after extraction of MLCC leachate (data for other metals not shown for clarity).

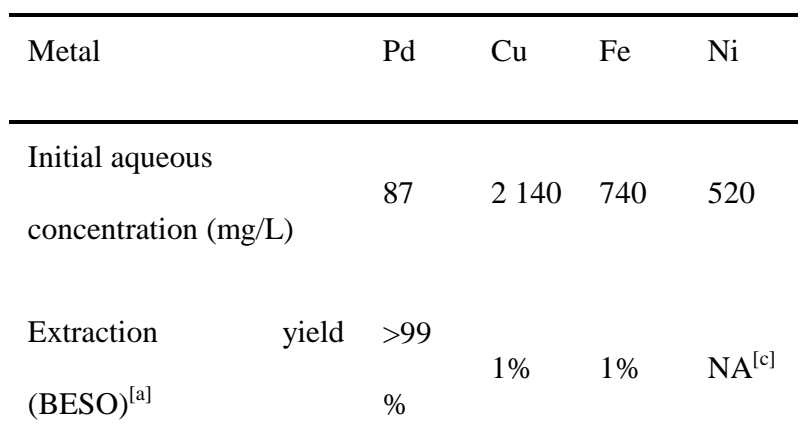




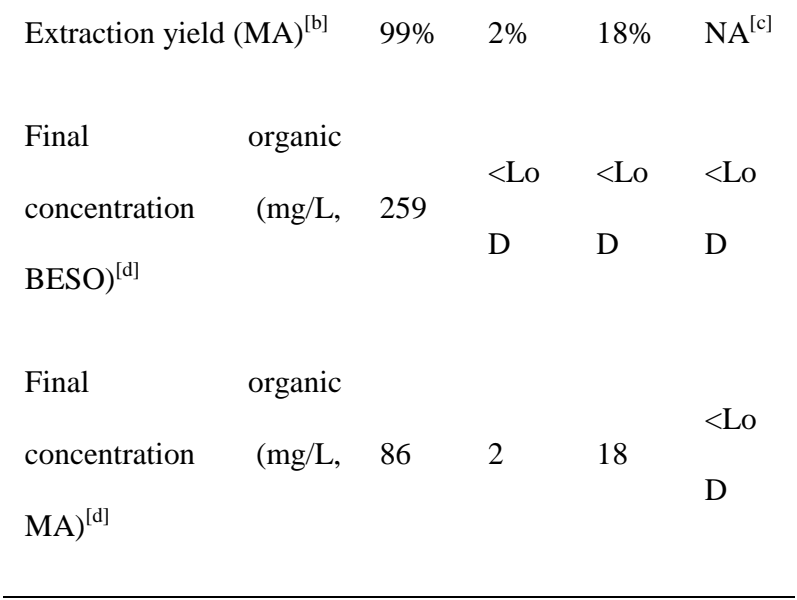

[a] Organic phase: BESO 0,2 M in n-heptane, one stage, aqueous/organic phase volume ratio of 3.

[b] Organic phase: MA 0,2 M in toluene, two stages, aqueous/organic phase volume ratio of 2.

[c] NA: not applicable (the concentration of the metal was below the limit of quantification).

[d] After washing the organic phase with water, organic/aqueous phase volume ratio of 10 .
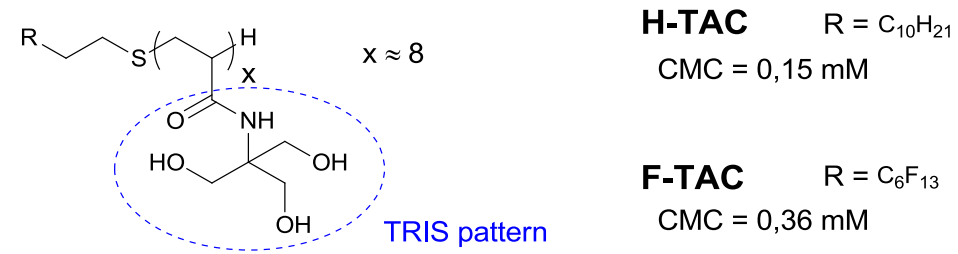

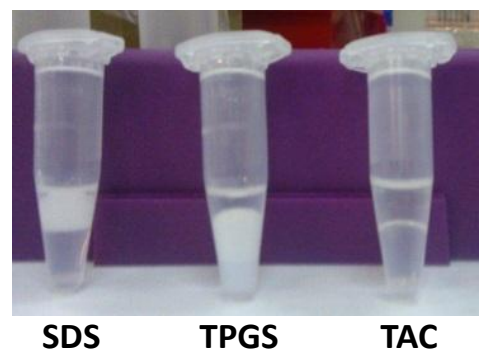

SDS

Figure 2. Amphiphiles employed for back-extraction and micellar catalysis (Tris-Acrylamide based hydrogenated and fluorinated TAC surfactants), and phase separation after centrifugation ( $3 \mathrm{~min}$ at $5000 \mathrm{rpm}$ ) of toluene and aqueous solutions of SDS, TPGS-750-M or F-TAC (concentration $20 \mathrm{mg} / \mathrm{mL}$ ).

In order to use a surfactant in the proposed process of Pd recovery (Figure 1), several features are necessary. First of all, the surfactant should be water soluble and not leach into the organic phase. Moreover, during the back-extraction step, it should lead to clean phase separation and efficient Pd backextraction. Finally, the surfactant has to be efficient for micellar catalysis, i.e. it must enable to run Pd catalysed reactions in aqueous media. In a preliminary evaluation of employable surfactants, we screened 
several non-ionic or ionic amphiphiles previously described as suitable for micellar catalysis, ${ }^{[34]}$ including sodium dodecyl sulphate (SDS), fatty alcohol polyglycol ethers (e.g. $\left.\mathrm{C}_{12} \mathrm{H}_{25}-(\mathrm{EO})_{23}-\mathrm{H}\right)$, alkyl or fluoroalkyl phosphate esters (e.g. fluorinated Zonyl UR). We also evaluated the vitamin-E based glycol ethers TPGS-750-M and TPGS-1000 (Structures given in Figure S3), classically employed to perform micellar catalysed reactions. ${ }^{[35]}$ All of them led to the formation of a stable emulsion after contacting and shaking with $n$-heptane or toluene, even after centrifugation (Figure 2).

Only surfactants derived from a Tris-ACrylamide polymerizable monomer (TAC) allowed a clean phase separation (Figure 2). TAC surfactants are obtained in a single step by free radical polymerization of an acryloyl monomer derived from tris(hydroxymethyl)acrylamide-methane (THAM) in the presence of an alkane- or a perfluoroalkanethiol as a transfer reagent (telogen), and have been prepared at the gramscale. ${ }^{[36]}$ These oligomers, perfectly water soluble for average degrees of polymerization (DPn $\left.\geq 4\right)$, have been developed for variable applications from drug delivery ${ }^{[37,38]}$ and theranostics ${ }^{[39]}$ to extraction and stabilization of membrane proteins. ${ }^{[40]}$ We focused in the present study on two molecules of this family (Figure 2), a fluorinated one (F-TAC, with a $\mathrm{C}_{6} \mathrm{~F}_{13} \mathrm{CH}_{2} \mathrm{CH}_{2}$ chain) and a hydrogenated one (H-TAC, with a $\mathrm{C}_{12} \mathrm{H}_{25}$ chain). Both have hydrophobic chains of comparable molecular volume, and similar critical micellar concentration (CMC).

Before studying the back-extraction of Pd(II), we checked whether TAC surfactants can be employed in order to perform Pd-catalyzed reaction in micellar media. Latter reactions have been developed using vitamin-E derived surfactants such as TPGS-750-M as stated before, but good yields and conversion rates with various classical ionic or non-ionic surfactants have also been previously reported. ${ }^{[34]}$ As a model reaction, a Suzuki-Miyaura ${ }^{[5,41]}$ cross-coupling reaction was chosen (Scheme 1). Yields obtained with both fluorinated or hydrogenated TAC surfactants were very satisfactory, only slightly lower than those obtained with TPGS-750-M, in conditions optimized for TPGS-750-M (Table 2). These conditions are not trivial, as only $1,1 \mathrm{~mol} \% \mathrm{Pd}(\mathrm{II})$ is employed. Using a lower amount of $\mathrm{Pd}(\mathrm{II})$ led to a drastic drop in yield using TPGS-750-M. 


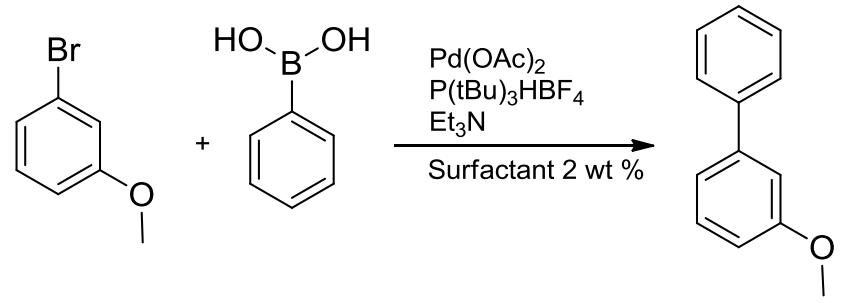

Scheme 1. Suzuki-Miyaura reaction employed as model reaction throughout the study.

Table 2. Effect of surfactant and palladium source on outcome of Suzuki reaction.

\begin{tabular}{llcc}
\hline Entry & Surfactant & Yield (\%) & Yield (\%) \\
& & Pd(OAc) $)_{2}$ & Recycled \\
& & & $\mathrm{Pd}$ \\
& & & $\mathrm{NA}^{[\mathrm{a}]}$ \\
\hline 1 & TPGS-750-M & 95 & 70 \\
3 & H-TAC & 85 & 77 \\
\hline
\end{tabular}

[a] NA: Not applicable

Pd back-extraction studies were systematically conducted on model organic phases containing Pd(II) only, of similar concentration (about $200 \mathrm{mg} / \mathrm{L}$ ), with a phase volume ratio of 1 . With a diluted aqueous $\mathrm{HNO}_{3}$ solution - preferred to water in order to avoid hydrolysis of the Pd(II) cation - without surfactant, the back-extraction yield reaches $55 \%$ in the case of MA, and 23\% with BESO (Figure 3). To our delight, the sole addition of TAC surfactant to the aqueous phase increased the Pd back-extraction yield. With both H-TAC and F-TAC, almost quantitative back-extraction could be observed when $1 \%$ surfactant was added in the aqueous phase (Figure 3). However, cruds (precipitates) were observed at the interphase from $1 \%$ weight surfactant concentration, especially with H-TAC. These cruds generally lead to decreased back-extraction yields on higher scale, and need to be avoided. We did not investigate their origin, but they seem related to the presence of ions in the system, as the phenomenon was independent of the choice of organic solvent and extractant, and as no phase separation issue was encountered without $\mathrm{HNO}_{3}$ and $\mathrm{Pd}(\mathrm{II})$ in the aqueous phase. F-TAC appears as the optimal surfactant, although it is possible 
to work with 2 wt $\% \mathrm{H}-\mathrm{TAC}$ as long as stirring is not too vigorous. The Pd back extraction from a BESO organic phase is particularly striking, as no specific $\mathrm{Pd}(\mathrm{II})$ chelating moiety is grafted on the surfactant. The exact coordination mode of Pd(II) will be studied later on, in order to determine the exact interactions between surfactant and metal. NMR analyses after back-extraction in a deuterated aqueous solution (see supplementary information, Figure S4) demonstrated that the quantities of $n$-heptane and BESO carried along into the aqueous phase with palladium are negligible compared to the total organic phase volume, so that it is possible that a $\mathrm{Pd}(\mathrm{II})$-BESO complex is involved in the back-extraction as the BESO quantity is of same order of magnitude as the Pd quantity. We also checked that no TAC surfactant migrated into the organic phase during the process (Figure S5). It is finally important to mention that Pd(II) aqueous micellar solutions obtained after back-extraction are stable for months, and that no Pd(II) hydrolysis was observed.
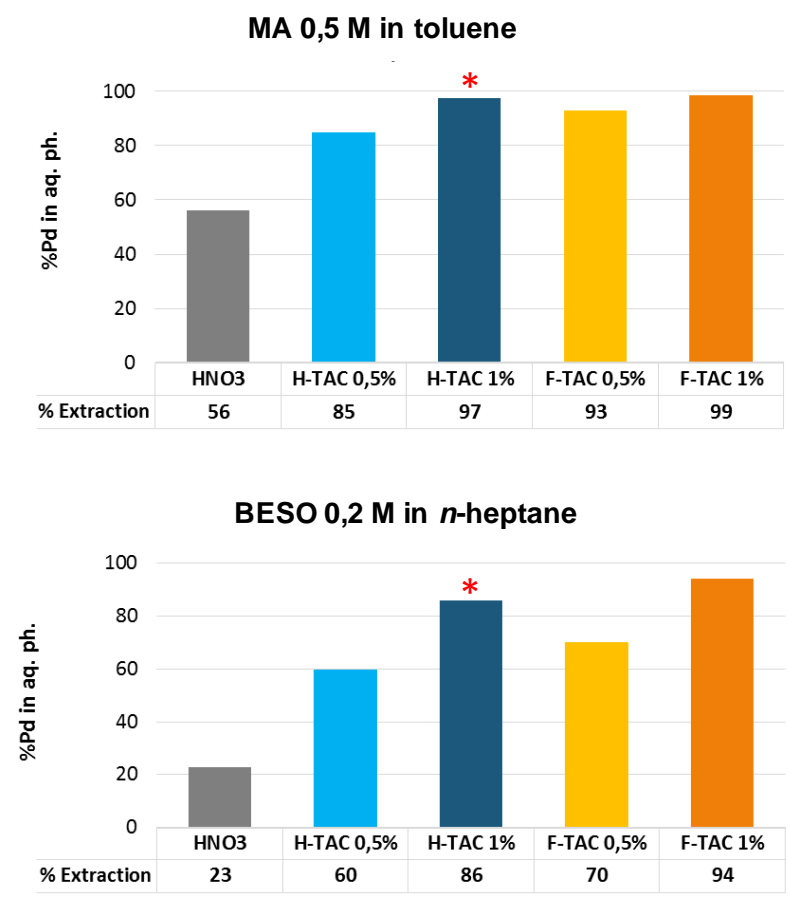

Figure 3. Top: Back-extraction of Pd(II) from a 0,5 M MA in toluene organic phase into an aqueous H- or F-TAC based solution. Bottom: Back-extraction of Pd(II) from a 0,2 M BESO in $n$-heptane organic phase into an aqueous H- or F-TAC based solution. * denotes the presence of cruds at the interface. 
Aqueous micellar solutions containing Pd(II) were then evaluated in the Suzuki-Miyaura reaction described beforehand. The only difference lies in the $\mathrm{Pd}(\mathrm{II})$ source, as well-defined solid $\mathrm{Pd}(\mathrm{OAc})_{2}$ is replaced by a solution of $\mathrm{Pd}(\mathrm{II})$ in aqueous $\mathrm{H}$ - or F-TAC solution. The Pd concentration in latter solutions also depends on the initial Pd concentration in the aqueous solution arising from leaching of WEEE. The final concentration can be higher than the initial one, thanks to concentrating extractions performed with unequal volumes of aqueous and organic phases (Table 1). Starting from a model aqueous solution containing $\mathrm{Pd}(100 \mathrm{mg} / \mathrm{L}), \mathrm{Fe}(1000 \mathrm{mg} / \mathrm{L})$ and $\mathrm{Cu}(2000 \mathrm{mg} / \mathrm{L})$, we were able to prepare aqueous $\mathrm{H}$ - or F-TAC solutions containing Pd(II) at concentrations between 650 and $900 \mathrm{mg} / \mathrm{L}$ (Table 3). No $\mathrm{Cu}$ nor $\mathrm{Fe}$ were detected in the final aqueous solutions, although (voluntarily) the $\mathrm{Fe}$ quantity in the initial model solution was set higher than that of real leachate solution.

Table 3. Composition of aqueous micellar solutions prepared from a $3 \mathrm{M}$ aqueous $\mathrm{HNO}_{3}$ solution containing Pd (100 mg/L), Fe (1 $000 \mathrm{mg} / \mathrm{L})$ and $\mathrm{Cu}(2000 \mathrm{mg} / \mathrm{L})$ using BESO 0,2 $\mathrm{M}$ in $n$-heptane.

\begin{tabular}{|c|c|c|c|c|}
\hline Entry & $\begin{array}{l}\text { Surfactant } \\
(2 \mathrm{wt} \%)\end{array}$ & $\begin{array}{l}\text { Extraction } \\
\text { conditions }^{[\mathrm{a}]}\end{array}$ & $\begin{array}{l}\text { Back- } \\
\text { extraction } \\
\text { conditions }^{[a]}\end{array}$ & $\begin{array}{l}\text { Final Pd(II) } \\
\text { concentration }\end{array}$ \\
\hline 1 & H-TAC & $\begin{array}{c}\mathrm{A} / \mathrm{O}=3 \\
(99 \% \text { yield })\end{array}$ & $\begin{array}{l}\mathrm{O} / \mathrm{A}=2,5 \\
(86 \% \text { yield })\end{array}$ & $630 \mathrm{mg} / \mathrm{L}$ \\
\hline 2 & H-TAC & $\begin{array}{c}\mathrm{A} / \mathrm{O}=10 \\
(94 \% \text { yield })\end{array}$ & $\begin{array}{c}\mathrm{O} / \mathrm{A}=1 \\
\text { (94\% yield) }\end{array}$ & $880 \mathrm{mg} / \mathrm{L}$ \\
\hline 3 & F-TAC & $\begin{array}{c}\mathrm{A} / \mathrm{O}=3 \\
(99 \% \text { yield })\end{array}$ & $\begin{array}{l}\mathrm{O} / \mathrm{A}=2,5 \\
\text { (92\% yield) }\end{array}$ & $680 \mathrm{mg} / \mathrm{L}$ \\
\hline 4 & F-TAC & $\begin{array}{c}\mathrm{A} / \mathrm{O}=10 \\
(94 \% \text { yield })\end{array}$ & $\begin{array}{c}\mathrm{O} / \mathrm{A}=1 \\
\text { (97\% yield) }\end{array}$ & $910 \mathrm{mg} / \mathrm{L}$ \\
\hline
\end{tabular}

[a] $\mathrm{A} / \mathrm{O}=$ aqueous to organic phase volume ratio

[b] $\mathrm{O} / \mathrm{A}=$ organic to aqueous phase volume ratio

It is preferable to work at low aqueous to organic phase volume ratio for the extraction process, and high organic to aqueous phase volume ratio for the back-extraction process (Table 3, entries 1 and 3) as the Pd that remains in the organic phase after incomplete back-extration is not lost: it is possible to recycle the 
organic phase containing a small Pd hold-up, as it is not deleterious to its extraction properties. ${ }^{[19]}$ When using recycled $\mathrm{Pd}$, in order to keep the Pd quantity constant relative to cross-coupling reaction reagents, we needed to adapt the amount of surfactant solution employed in the cross-coupling reaction, i.e. we increased the volume of aqueous solution employed in order to reach the $1,1 \mathrm{~mol} \% \mathrm{Pd}$ amount required. A $1150 \mathrm{mg} / \mathrm{L}$ Pd solution would lead to exactly the same volume of aqueous surfactant solution employed in the cross-coupling reaction. As a consequence, with recycled Pd, there was a dilution of reaction medium by a factor 1,2 to 1,7 . Yields obtained with both $\mathrm{H}$ - and F-TAC surfactant solutions are very satisfactory (Table 1); a 77\% yield was obtained with the F-TAC solution (Table 3, entry 3), in comparison with the $85 \%$ yield obtained with commercial $\mathrm{Pd}(\mathrm{OAc})_{2}$. The nitric acid concentration in final F-TAC solution (Table 3, entry 3) was determined experimentally to be 0,1 M. This acid was neutralized using 1 extra equivalent of trimethylamine, and did not set any peculiar issue to the use of recycled $\mathrm{Pd}$.

To our knowledge, this result represents the first proof of concept of a chemical reaction catalysed with palladium directly recovered from waste. In this work, the recovered Pd is purified through a solvent extraction process, and the presence of possible impurities was checked: after washing of the organic phase, $\mathrm{Fe}$ and $\mathrm{Cu}$, the major impurities, were not detected in the organic solution. They were neither detected in the final aqueous Pd solution employed for catalysis: Pd purity is above $99 \%$ regarding Fe. This purification is ensured by the selective Pd extraction with BESO. The use of a solvent extraction process has two further key features: it enables Pd concentration (up to 10-fold concentration between leaching solution and surfactant solution for catalysis) and separation of Pd from the nitric acid employed for leaching (initially $3 \mathrm{M}$ aqueous solution). The extracting molecule (BESO) presents no peculiar health or environmental hazards according to its safety datasheet, the organic solvent employed ( $n$ heptane) is amongst the best possible according to green chemistry guidelines considering that water solubility has to be minimal. The surfactant employed in the system is easily accessible and has been developed for medical applications. Nitric acid is employed for the leaching operation, and it has to be mentioned that this reagent has a very low impact on human health and environment in comparison with available alternatives, especially considering that is it employed diluted in water. To our knowledge, 
leaching of Pd can also be envisioned using halide based reagents, which also set problems (chloride ions in oxidizing media lead to chlorine offgas, and iodine is very toxic to aquatic life and harmful according to ECHA). The amount of waste generated by the proposed process is very low (only $10 \%$ of the volume of the organic phase employed), and especially in comparison with previously performing processes developed at our laboratory, which are already very well positioned. ${ }^{[13,19]}$ It is key to mention that backextraction of Pd from a BESO based organic phase is impossible without the use of a specific aqueous layer, which has then to be processed in order to isolate Pd. As mentioned before, Pd is usually isolated by precipitation after addition of ammonia then hydrochloric acid. A detailed life-cycle assessment would enable a more precise evaluation of the impact of waste reduction.

In the continuation of this work, we will pursue the study of impurities influence (metallic ions and acid) and see how we can further simplify the process. We will also consider different reactions, including more demanding reactions which rely on sole Pd catalysis such as Buchwald-Hartwig reactions. ${ }^{[42]}$ Suzuki-Miyaura reactions are indeed less sensitive to metallic impurities such as Fe, and it has even been recently proven that Fe nanoparticles containing only trace Pd can act as efficient catalyst for this reaction. ${ }^{[43]}$ The system we propose in this work is also of interest considering the work-up at larger scale of cross-coupling reactions performed in micellar medium: there is no emulsion generated during the Pd back-extraction process with TAC-surfactants, and similarly we did not encounter any phase separation issue during extraction of reaction product in diethyl ether after reaction. The catalytic system remains in the aqueous layer and no Pd was detected in the final product.

\section{Conclusion}

As a conclusion, we propose an original combination of hydrometallurgic process dedicated to $\mathrm{Pd}$ recovery from electronic waste and surfactant aqueous formulation, which enables the direct use of recycled $\mathrm{Pd}$ in important chemical reactions. The selective $\mathrm{Pd}$ extraction process enables the straightforward preparation of a Pd aqueous solution employable as a reaction medium for SuzukiMiyaura reaction. The co-extracted acid quantity is manageable, and the other metallic impurities, mainly $\mathrm{Cu}$ and $\mathrm{Fe}$, eliminated using a small aqueous washing, so that the amount of generated waste is 
minimal. It is of course arguable that Suzuki-Miyaura reactions can be performed using lower amount of $\mathrm{Pd}$, but the aim of this work is not to develop specific catalysts with very high turnover in specific conditions, but to replace simple commercial $\mathrm{Pd}(\mathrm{OAc})_{2}$ using classical ligands in the simplest reaction medium: water. This novel approach is promising as it opens the door towards open cycles in circular economy, going from waste to valuable compounds, a key for a better use of our resources, and the emergence of performing sustainable chemical industry.

\section{Experimental Section}

Determination of metal concentration in solutions: Aliquots of aqueous phases $(100-250 \mu \mathrm{L})$ were directly diluted into a $2 \% \mathrm{HNO}_{3}$ aqueous solution. Metals contained in the aliquots of the organic phases (100-200 $\mu \mathrm{L})$ were back-extracted with $800 \mu \mathrm{L}$ of an aqueous $0.1 \mathrm{M}$ thiourea solution at $20-22^{\circ} \mathrm{C}$ for $1 \mathrm{~h}$. Both phases were separated, and $500 \mu \mathrm{L}$ of the resulting aqueous solution were taken and diluted into a $2 \% \mathrm{HNO}_{3}$ aqueous solution. Concentrations of each metal in so-obtained $2 \% \mathrm{HNO}_{3}$ aqueous phases were determined by inductively coupled plasma atomic emission spectroscopy (ICP/AES, SPECTRO ARCOS ICP Spectrometer, AMETEK Materials Analysis). Given concentrations are calculated as the means of three replicates on three different wavelengths for each metal; relative standard deviations were determined and lie between 1 and $4 \%$.

General experimental procedure for the preparation of organic Pd(II) solutions from aqueous mixtures of metallic cations: An aqueous nitrate phase containing the metallic cations, prepared either from electronic waste according to our previously reported procedure ${ }^{[19]}$ (details are also given in supplementary material), or from the corresponding metallic salts $\left(\mathrm{Pd}\left(\mathrm{NO}_{3}\right)_{2} \cdot \mathrm{xH}_{2} \mathrm{O}, \mathrm{Fe}\left(\mathrm{NO}_{3}\right)_{3} \cdot 9 \mathrm{H}_{2} \mathrm{O}\right.$, $\mathrm{Cu}\left(\mathrm{NO}_{3}\right)_{2} \cdot 3 \mathrm{H}_{2} \mathrm{O}$ ) diluted in $3 \mathrm{M}$ aqueous $\mathrm{HNO}_{3}$, was contacted to an organic phase (either $\mathrm{MA} 0,5 \mathrm{M}$ in toluene or BESO $0,2 \mathrm{M}$ in $n$-heptane) in $15 \mathrm{~mL}$ plastic tubes with a ratio of aqueous to organic phase volumes between 1 and 10 (see text for details). The mixture was vigorously shaken using an IKAVibrax VXR basic shaker at $1200 \mathrm{rpm}$ for $1 \mathrm{~h}$ at $20^{\circ} \mathrm{C}$. The vials were removed and let to stand for 5 min and the phases were separated. The resulting organic phase was washed with water (ratio of organic 
to aqueous phase volumes equal to 10 , contact time $15 \mathrm{~min}$ ), and the phases were separated as described above. The resulting organic phase was aliquoted for analysis of metals with ICP/AES as described above.

General experimental procedure for the back-extraction with aqueous micellar solutions: An organic $\mathrm{Pd}(\mathrm{II})$ solution was contacted to an aqueous solution of surfactant of concentration between 0,5 and $2 \mathrm{wt}$ $\%$, with a ratio of organic to aqueous phase volumes between 1 and 2,5 (see text for exact values). The mixture was gently stirred using an IKA-Vibrax VXR basic shaker at $200 \mathrm{rpm}$ for $1 \mathrm{~h}$ at $20^{\circ} \mathrm{C}$. The vials were removed and let to stand for 5 min (or centrifuged for 5 min to achieve complete phase separation) and the phases were separated. The resulting aqueous phase was aliquoted for analysis of metals with ICP/AES as described above.

General experimental procedure for Suzuki-Miyaura coupling in micellar medium: Bromoanisole (1 equiv.), phenyl boronic acid (1,5 equiv.) and tri-tert-butylphosphonium tetrafluoroborate $(4,4 \mathrm{~mol} \%)$ were weighed and placed in an $2 \mathrm{~mL}$ plastic vial. Using $\mathrm{Pd}(\mathrm{OAc})_{2}$ : A $2 \mathrm{wt} \%$ solution of surfactant freshly prepared and previously degassed under argon containing palladium(II) acetate $(1,1$ mol \%) was added to the solids $(1 \mathrm{~mL} / \mathrm{mmol})$. Using recycled Pd: A 2 wt $\%$ solution of surfactant prepared after back-extraction of organic phase and previously degassed under argon was added to the solids (volume adjusted in order to reach $1,1 \mathrm{~mol} \% \mathrm{Pd}$, i.e. 1,2 to $1,7 \mathrm{~mL} / \mathrm{mmol}$ ). The resulting mixture was homogenised and degassed with argon bubbling ( $5 \mathrm{~min})$. Then triethylamine (3-4 equiv) was added, and the resulting mixture was stirred using an IKA-Vibrax VXR basic shaker at $1200 \mathrm{rpm}$ for $18 \mathrm{~h}$ at $20^{\circ} \mathrm{C}$. The mixture was extracted twice with $3 \mathrm{~mL}$ of diethyl ether. The combined organic layers were concentrated in vacuo and the crude residue was purified by flash chromatography on silica gel using cyclohexane and ethyl acetate as eluents.

\section{Acknowledgements}


The authors are grateful to the LabEx ChemiSyst for funding the PhD thesis grant of V. Lacanau (ANR-10LABX-05-01).

Keywords: Palladium $\bullet$ Recycling $\bullet$ Cross-coupling $\bullet$ Amphiphiles $\bullet$ Homogeneous catalysis

[1] J. Tsuji, Palladium Reagents and Catalysts: New Perspectives for the 21st Century, Wiley, Hoboken, NJ, 2004.

[2] M. Pagliaro, V. Pandarus, R. Ciriminna, F. Béland, P. Demma Carà, ChemCatChem 2012, 4, 432-445.

[3] B. Lipshutz, S. Ghorai, Transition-Metal-Catalyzed Cross-Couplings Going Green: In Water at Room Temperature, 2008.

[4] B. H. Lipshutz, S. Ghorai, M. Cortes-Clerget, Chemistry - A European Journal 2018, 24, 6672-6695.

[5] V. Polshettiwar, A. Decottignies, C. Len, A. Fihri, ChemSusChem 2010, 3, 502-522.

[6] A. Cowley, 2019.

[7] N. Supanchaiyamat, A. J. Hunt, ChemSusChem 2019, 12, 397-403.

[8] L. Erdmann, T. E. Graedel, Environmental Science \& Technology 2011, 45, 7620-7630.

[9] T. E. Graedel, E. M. Harper, N. T. Nassar, P. Nuss, B. K. Reck, Proceedings of the National Academy of Sciences 2015, 112, 4257-4262.

[10] A. Işıldar, E. R. Rene, E. D. van Hullebusch, P. N. L. Lens, Resources, Conservation and Recycling 2018, 135, 296312.

[11] M. Kaya, Waste Management 2016, 57, 64-90.

[12] Y. Ding, S. Zhang, B. Liu, H. Zheng, C. Chang, C. Ekberg, Resources, Conservation and Recycling 2019, 141, 284298.

[13] R. Mastretta, R. Poirot, D. Bourgeois, D. Meyer, Solvent Extraction and Ion Exchange 2019, 37, 140-156.

[14] J. Ponou, L. P. Wang, G. Dodbiba, T. Fujita, Separation and Purification Technology 2018, 191, 86-93.

[15] J. Hao, Y. Wang, Y. Wu, F. Guo, Resources, Conservation and Recycling 2020, 157, 104787.

[16] J. Rydberg, Ed., Solvent Extraction Principles and Practice, M. Dekker, New York, 2004.

[17] R. Poirot, D. Bourgeois, D. Meyer, Solvent Extraction and Ion Exchange 2014, 32, 529-542.

[18] R. Poirot, X. Le Goff, O. Diat, D. Bourgeois, D. Meyer, ChemPhysChem 2016, 17, 2112-2117.

[19] D. Bourgeois, V. Lacanau, R. Mastretta, C. Contino-Pépin, D. Meyer, Hydrometallurgy 2020, 191, 105241.

[20] F. K. Crundwell, M. S. Moats, V. Ramachandran, T. G. Robinson, W. G. Davenport, in Extractive Metallurgy of Nickel, Cobalt and Platinum Group Metals, Elsevier, 2011, pp. 489-534.

[21] S. K. Ritter, $C \& E N$ 2017, 95, 26-32. 
[22] A. Serpe, F. Bigoli, M. C. Cabras, P. Fornasiero, M. Graziani, M. L. Mercuri, T. Montini, L. Pilia, E. F. Trogu, P. Deplano, Chemical Communications 2005, 1040.

[23] V. Gombac, T. Montini, A. Falqui, D. Loche, M. Prato, A. Genovese, M. L. Mercuri, A. Serpe, P. Fornasiero, P. Deplano, Green Chem. 2016, 18, 2745-2752.

[24] K. A. Jantan, C. Y. Kwok, K. W. Chan, L. Marchiò, A. J. P. White, P. Deplano, A. Serpe, J. D. E. T. Wilton-Ely, Green Chem. 2017, 19, 5846-5853.

[25] K. A. Jantan, K. W. Chan, L. Melis, A. J. P. White, L. Marchiò, P. Deplano, A. Serpe, J. D. E. T. Wilton-Ely, ACS Sustainable Chem. Eng. 2019, acssuschemeng.9b01877.

[26] Z. A. S. Harumain, H. L. Parker, A. Muñoz García, M. J. Austin, C. R. McElroy, A. J. Hunt, J. H. Clark, J. A. Meech, C. W. N. Anderson, L. Ciacci, et al., Environ. Sci. Technol. 2017, 51, 2992-3000.

[27] G. Clavé, F. Pelissier, S. Campidelli, C. Grison, Green Chemistry 2017, 19, 4093-4103.

[28] C. Garel, B.-L. Renard, V. Escande, A. Galtayries, P. Hesemann, C. Grison, Applied Catalysis A: General 2015, 504, $272-286$.

[29] I. Birloaga, F. Vegliò, in Waste Electrical and Electronic Equipment Recycling, Elsevier, 2018, pp. $95-113$.

[30] G. Prabaharan, S. P. Barik, B. Kumar, Waste Management 2016, 52, 302-308.

[31] H. Yang, J. Liu, J. Yang, Journal of Hazardous Materials 2011, 187, 393-400.

[32] K. Yoo, J. Lee, K. Lee, B. Kim, M. Kim, S. Kim, B. D. Pandey, Mater. Trans. 2012, 53, 2175-2180.

[33] D. Bourgeois, A. El Maangar, S. Dourdain, Current Opinion in Colloid \& Interface Science 2020, 46, 36-51.

[34] B. H. Lipshutz, B. R. Taft, Organic Letters 2008, 10, 1329-1332.

[35] B. H. Lipshutz, S. Ghorai, A. R. Abela, R. Moser, T. Nishikata, C. Duplais, A. Krasovskiy, R. D. Gaston, R. C. Gadwood, The Journal of Organic Chemistry 2011, 76, 4379-4391.

[36] B. Boyer, G. Lamatya, J. M. Moussamou-Missima, A. A. Pavia, B. Pucci, J. P. Roque, Tetrahedron 1992, 48, 24152426.

[37] S. Jasseron, C. Contino-Pépin, J. C. Maurizis, M. Rapp, B. Pucci, European Journal of Medicinal Chemistry 2003, 38, $825-836$.

[38] C. Contino-Pépin, A. Parat, C. Patinote, W. A. Roscoe, S. J. Karlik, B. Pucci, ChemMedChem 2010, 5, $2057-2064$.

[39] K. Astafyeva, L. Somaglino, S. Desgranges, R. Berti, C. Patinote, D. Langevin, F. Lazeyras, R. Salomir, A. Polidori, C. Contino-Pépin, et al., Journal of Materials Chemistry B 2015, 3, 2892-2907.

[40] K.-H. Park, C. Berrier, F. Lebaupain, B. Pucci, J.-L. Popot, A. Ghazi, F. Zito, Biochemical Journal 2007, 403, 183187. 
[41] C. Doebelin, P. Wagner, I. Bertin, F. Simonin, M. Schmitt, F. Bihel, J.-J. Bourguignon, RSC Advances 2013, 3, 10296.

[42] P. Wagner, M. Bollenbach, C. Doebelin, F. Bihel, J.-J. Bourguignon, C. Salomé, M. Schmitt, Green Chem. 2014, 16, $4170-4178$.

[43] S. Handa, Y. Wang, F. Gallou, B. H. Lipshutz, Science 2015, 349, 1087-1091. 
On a fait la une !

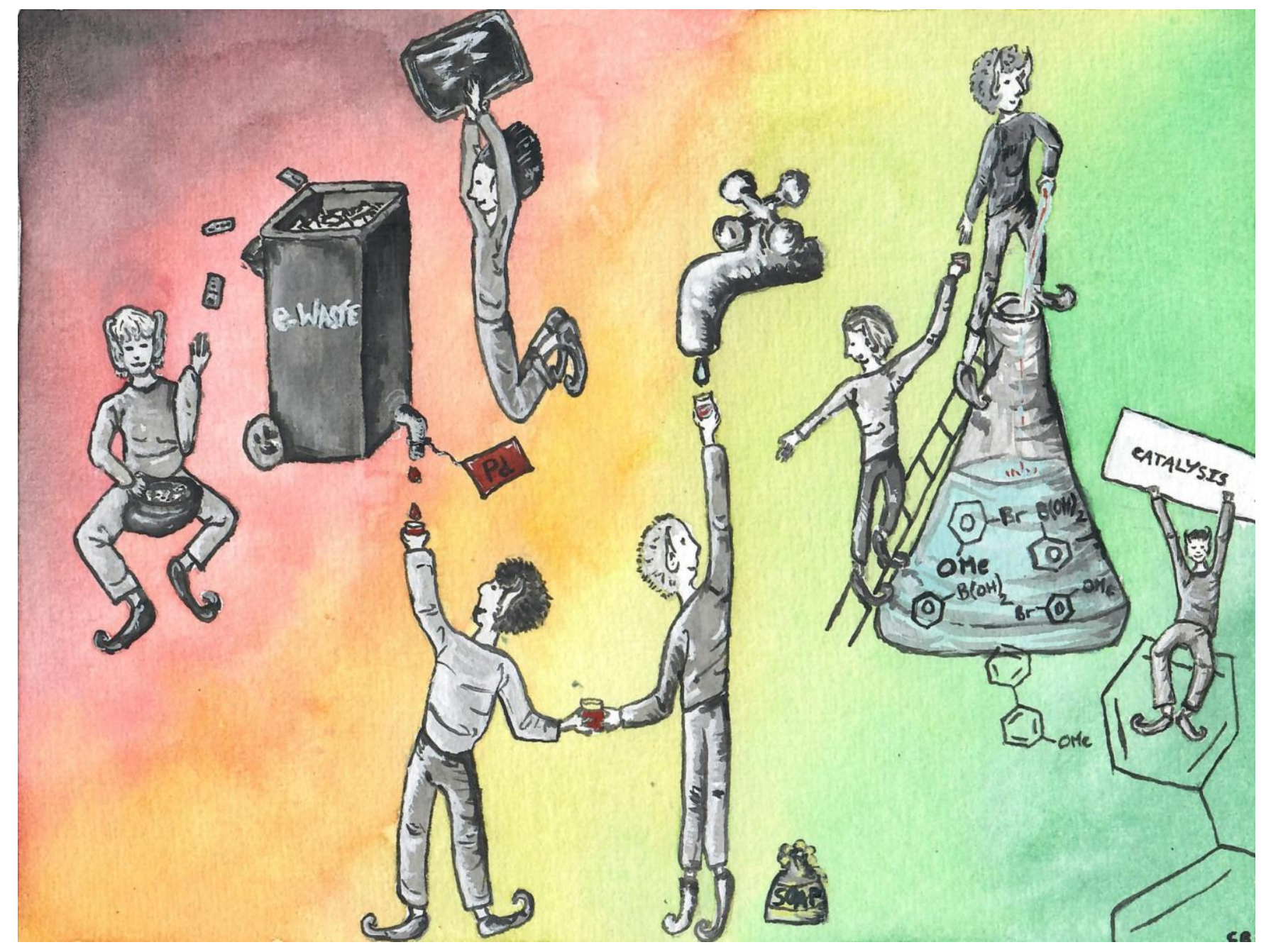

